\title{
Unloading of right ventricle by bidirectional superior cavopulmonary anastomosis in hypoplastic left heart syndrome patients promotes remodeling of systemic right ventricle but does not improve tricuspid regurgitation
}

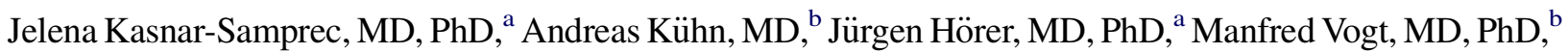 \\ Julie Cleuziou, $\mathrm{MD},{ }^{\mathrm{a}}$ Rüdiger Lange, $\mathrm{MD}, \mathrm{PhD},{ }^{\mathrm{a}}$ and Christian Schreiber, $\mathrm{MD}, \mathrm{PhD}^{\mathrm{a}}$
}

\begin{abstract}
Objective: To evaluate the influence of volume unloading by bidirectional superior cavopulmonary anastomosis on the systemic right ventricle in patients with hypoplastic left heart syndrome.

Methods: A total of 90 consecutive patients with hypoplastic left heart syndrome, who had survived the early postoperative period after bidirectional superior cavopulmonary anastomosis, were studied. Seven patients were excluded because of tricuspid valve surgery before or in association with bidirectional superior cavopulmonary anastomosis. The echocardiograms of the remaining 83 patients were reevaluated for tricuspid valve regurgitation and the size of the tricuspid annulus before bidirectional superior cavopulmonary anastomosis and at the last available follow-up examination before total cavopulmonary connection.
\end{abstract}

\begin{abstract}
Results: Echocardiograms were performed a median of 5 days before bidirectional superior cavopulmonary anastomosis. Tricuspid valve regurgitation was graded as 0 in 11 patients, I in 37 patients, II in 24 patients, and III in 11 patients. Follow-up echocardiograms were performed a median of 17 months after bidirectional superior cavopulmonary anastomosis. Postoperatively, tricuspid valve regurgitation was graded as 0 in 14 patients, I in 37 patients, II in 21 patients, III in 6 patients, and IV in 5 patients. Postoperatively, the mean $Z$ value of the tricuspid annulus stayed the same in patients with significant tricuspid valve regurgitation (grade III or IV) after bidirectional superior cavopulmonary anastomosis but had decreased in the remaining patients. No significant change was seen in the level of tricuspid valve regurgitation after bidirectional superior cavopulmonary anastomosis compared with the preoperative data.
\end{abstract}

Conclusions: The relative size of the tricuspid annulus in patients with hypoplastic left heart syndrome decreases after bidirectional superior cavopulmonary anastomosis, most likely owing to volume unloading and promotion of the remodeling of the systemic right ventricle. However, this remodeling of the right ventricle does not improve the grade of tricuspid regurgitation. (J Thorac Cardiovasc Surg 2012;144:1102-9)

Significant tricuspid valve (TV) regurgitation (TR) is a risk factor for early and late adverse outcomes ${ }^{1,2}$ in the treatment of patients with hypoplastic left heart syndrome (HLHS). TV function in these patients is determined by several interrelated factors, including volume overload and dilation of the right ventricle (RV), dilation of the TV annulus, structural abnormalities of the tricuspid leaflets, and deteriorating $\mathrm{RV}$ function. ${ }^{3}$

From the Departments of Cardiovascular Surgery ${ }^{\mathrm{a}}$ and Pediatric Cardiology and Congenital Heart Defects, ${ }^{\mathrm{b}}$ Deutsches Herzzentrum München an der Technischen Universität München, Munich, Germany.

Disclosures: Authors have nothing to disclose with regard to commercial support.

J.K.-S. and A. K. were equally contributing authors.

Read at the 92nd Annual Meeting of The American Association for Thoracic Surgery, San Francisco, California, April 28-May 2, 2012.

Received for publication April 25, 2012; revisions received July 22, 2012; accepted for publication Aug 1, 2012; available ahead of print Sept 10, 2010.

Address for reprints: Jelena Kasnar-Samprec, MD, PhD, Department of Cardiovascular

Surgery, Deutsches Herzzentrum München an der Technischen Universität München, Lazarettstraße 36, Munich 80636 Germany (E-mail: samprec@dhm.mhn.de).

$0022-5223 / \$ 36.00$

Copyright (c) 2012 by The American Association for Thoracic Surgery

http://dx.doi.org/10.1016/j.jtcvs.2012.08.012
Three-stage surgical univentricular palliation is an established treatment strategy for HLHS. ${ }^{4}$ The construction of a bidirectional superior cavopulmonary anastomosis (BSCPA), which follows the initial Norwood operation, alters the source of pulmonary blood flow and reduces the volume load of the systemic RV. ${ }^{5}$ The decreased ventricular volume seems to reduce the rate of tricuspid annulus dilation. ${ }^{6}$ Some studies have suggested that the regurgitation of the atrioventricular valve in single-ventricle patients might improve after BSCPA without concomitant valvuloplasty. ${ }^{7}$

The objective of our study was to elucidate the influence of volume unloading by BSCPA on the systemic RV in the patients with HLHS and its influence on systemic TR. According to the results obtained, we wanted to discuss the possible clinical implications regarding TV repair at BSCPA.

\section{PATIENTS AND METHODS \\ Patient Selection}

We identified all patients with HLHS who had undergone Norwood I palliation and BSCPA from 2001 to 2010 from our institutional cardiothoracic surgical database. We performed a retrospective review of 90 


\section{Abbreviations and Acronyms \\ HLHS = hypoplastic left heart syndrome \\ RV = right ventricle/right ventricular \\ TAPSE $=$ tricuspid annular plane systolic excursion \\ TR $=$ tricuspid valve regurgitation \\ $\mathrm{TV}=$ tricuspid valve}

consecutive patients who had survived the early postoperative period after BSCPA. A total of 7 patients, in whom TV reconstruction or replacement had to be performed before $(n=2)$ or at BSCPA $(n=5)$ because of severe TR, were excluded from the final study group.

\section{Echocardiographic Examination}

Two echocardiograms from each patient $(n=83)$ were reevaluated by a single experienced observer: 1 before BSCPA (preoperatively) and the other at the last available follow-up point before total cavopulmonary connection (postoperatively).

The following measures were obtained: the degree of TR, morphology of the TV in the presence of significant regurgitation, the size of the TV annulus, tricuspid annular plane systolic excursion (TAPSE), and RV function. TR was graded qualitatively into 1 of 5 levels: absent (0), trivial (I), mild (II), moderate (III), or severe (IV). The grade was determined by the width and length of the insufficiency jet. Significant TR was defined as grade III or IV. The pathologic features of the TV were described for all patients with significant TR. TV annulus was measured as the maximum distance between the TV leaflet hinge points in the apical 4-chamber view. The size of the TV annulus was standardized to the body surface area of the patient at the time of echocardiography. ${ }^{8}$ TAPSE was measured using 2-dimensional echocardiography-guided M-mode recordings from the apical 4-chamber view, with the cursor placed at the free wall of the tricuspid annulus. To be able to compare the pre- and postoperative TAPSE values of the children with HLHS, the mean expected TAPSE values for age in the normal population were determined for each patient preoperatively and postoperatively ("normal TAPSE for age"). ${ }^{9}$ The measured TAPSE values were then compared with these values to obtain a TAPSE/age ratio according to the formula: TAPSE/age ratio $=$ (measured TAPSE/normal TAPSE for age) $\times 100$. A ratio of $100 \%$ would mean that the measured value is the same as the value for a healthy child of the same age. RV function was qualitatively graded as normal, mildly, moderately, or severely depressed ("eye balling").

\section{Missing Values}

The necessary loops for obtaining all the parameters could not be obtained from some of the echocardiograms performed during the early part of the study period. Consequently, 18 preoperative and 6 postoperative values were missing for TV annulus and 20 preoperative and 6 postoperative values for TAPSE were missing. The number of patients with missing values was not significantly different between the examined groups for any of these parameters.

\section{Statistical Analysis}

Descriptive statistics are described as frequencies and percentages for categorical variables. Continuous variables are expressed as the mean \pm standard deviation, if normally distributed, or median and range for a non-normal distribution. Fischer's exact test or McNemar's test was performed to detect significant differences between groups (2-tailed tests were used for all analyses). Continuous variables were compared between groups using the 2-tailed unpaired Student $t$ test and within the groups using the 2-tailed paired Student's $t$-test. All data were analyzed using SPSS software, version 19.0 (SPSS, Inc, Chicago, Ill).

The institutional review board approved the present retrospective follow-up study. The requirement for informed consent was waived. We all had full access to the data and take full responsibility for the integrity of the data.

\section{RESULTS}

The mean age at BSCPA was $4.4 \pm 1.5$ months, and mean weight was $5.29 \pm 0.89 \mathrm{~kg}$. Echocardiograms before BSCPA were performed a median of 5 days (range, 0-25) preoperatively. Follow-up echocardiograms were performed a median of 17 months (range, 7 days to 57 months) after BSCPA. For 5 patients, the follow-up echocardiogram was performed 7 to 14 days postoperatively and for another 4 patients 15 to 21 days postoperatively. All these children had travelled for surgery from another country, and details of more recent echocardiograms could not be obtained for the present study. In the remaining 74 patients, a follow-up echocardiogram was performed at least 1 month postoperatively. The mean age at the completion of univentricular palliation was $20.7 \pm 8.0$ months.

\section{TV Regurgitation}

Before BSCPA, TR was graded as 0 in 11 patients, $\mathrm{I}$ in 37 patients, II in 24 patients, and III in 11 patients (Figure 1, $A$ ). Postoperatively, TR was graded as 0 in 14 patients, I in 37 patients, II in 21 patients, III in 6 patients, and IV in 5 patients (Figure 1, $B$ ). No significant change was seen in the level of TR after BSCPA compared with the preoperative data $(P=.68$, patients with TR grade $\geq \mathrm{II}$ and $P=1.00$, patients with TR grade $\geq$ III).

The comparison of pre- and postoperative TR on an individual patient basis is presented in Table 1. The echocardiographic details of each patient with significant TR, including the underlying pathologic features of the tricuspid leaflets, are listed in Table 2.

The patients were divided into 3 groups. Group 1 included 65 patients who did not have significant TR either before or after BSCPA. Group 2 included 7 patients who had significant TR preoperatively but after BSCPA had nonsignificant TR. Finally, group 3 included 11 patients with significant TR postoperatively, regardless of the preoperative finding; before BSCPA, 4 had significant and 7 nonsignificant TR. The median follow-up period was similar in all groups (group 1, 17.0 months; group 2, 15.8 months; and group 3, 18.5 months).

\section{TV Annulus}

Figure 2 shows the mean $Z$ value of the TV annulus before and after BSCPA for all 3 groups. The mean $Z$ value of the TV annulus before BSCPA was significantly lower in group $1(0.98 \pm 0.82)$ than in group $2(1.84 \pm 0.69 ; P=.015)$ and tended to be lower than in group $3(1.54 \pm 0.66 ; P=.071)$. 

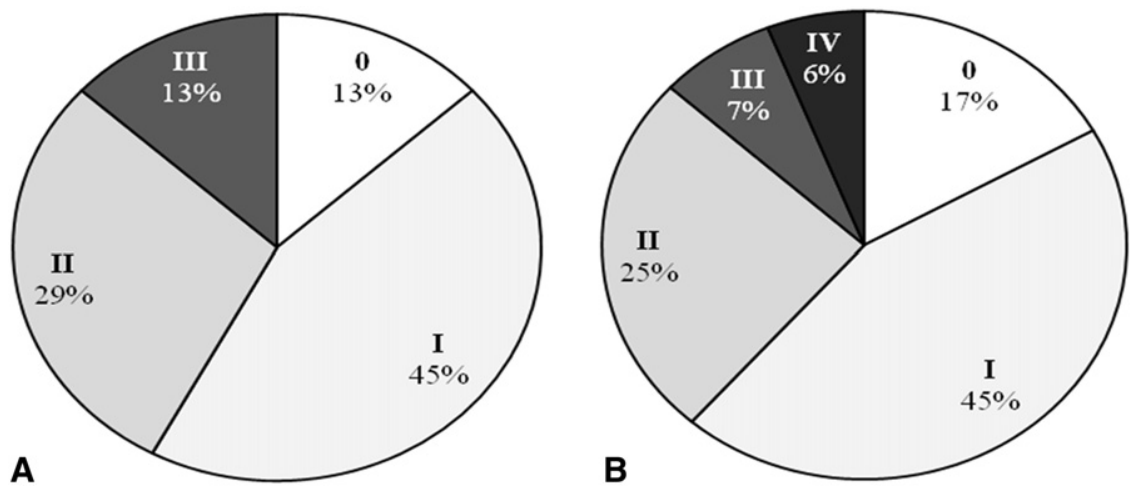

FIGURE 1. Percentage of patients according to grade of tricuspid regurgitation, (A) before and, (B) after bidirectional superior cavopulmonary anastomosis.

No statistically significant difference was seen in the preoperative $Z$ value of the tricuspid annulus between groups 2 and $3(P=.421)$. After BSCPA, the $Z$ value of the tricuspid annulus was lower in group $1(0.41 \pm 0.70)$ than in group 3 $(1.32 \pm 0.85 ; P=.008)$, while no statistically significant difference was found between group $2(0.87 \pm 0.54)$ and group $1(P=.101)$ or group $3(P=.215)$.

\section{Tricuspid Annular Plane Systolic Excursion}

Figure 3 shows the TAPSE/age ratio before and after BSCPA for all 3 groups. Before BSCPA, the TAPSE/age ratio was the same in all patients, lower than the expected value for the same age group of healthy patients. After BSCPA, the TAPSE/age ratio was greater in group 3 $(62.38 \pm 9.58)$ than in group $1(51.64 \pm 8.97 ; P=.006)$ or group $2(50.41 \pm 10.52 ; P=.033)$, while no difference was noted between groups 1 and $2(P=.775)$.

\section{RV Function}

Before BSCPA, RV function was normal in 79 patients $(95 \%)$, mildly reduced in $3(4 \% ; 1$ patient in group 1 and 2 patients in group 3), and moderately reduced in 1 patient (in group $2 ; 1 \%$ ). Reduced RV function was found more often in patients with significant TR than in those with nonsignificant TR. After BSCPA, RV function was normal in 72

TABLE 1. Comparison of pre- and postoperative tricuspid regurgitation

\begin{tabular}{lcrccc}
\hline & \multicolumn{5}{c}{ Postoperative TR } \\
\cline { 2 - 6 } Preoperative TR & $\mathbf{0}$ & I & II & III & IV \\
\hline 0 & $6 *$ & $3 \dagger$ & $2 \dagger$ & $0 \dagger$ & $0 \dagger$ \\
I & $5 \ddagger$ & $24 *$ & $7 \dagger$ & $1 \dagger$ & $0 \dagger$ \\
II & $2 \ddagger$ & $9 \ddagger$ & $7 *$ & $3 \dagger$ & $3 \dagger$ \\
III & $1 \ddagger$ & $1 \ddagger$ & $5 \ddagger$ & $2 *$ & $2 \dagger$ \\
IV & $0 \ddagger$ & $0 \ddagger$ & $0 \ddagger$ & $0 \ddagger$ & $0 *$ \\
\hline
\end{tabular}

$T R$, Tricuspid regurgitation; $B S C P A$, bidirectional superior cavopulmonary anastomosis. *Patients in whom TR severity stayed the same after BSCPA. †Patients in whom TR severity increased after BSCPA. $\ddagger$ Patients in whom TR severity decreased after BSCPA. patients, mildly reduced in 8 (5 in group 1,1 in group 2 , and 2 in group 3), moderately reduced in 1 patient (in group 3 ), and severely reduced in 2 patients (both in group 1).

In 3 of 4 patients with preoperative RV dysfunction, the function normalized after BSCPA. In 1 patient (with mildly decreased RV function), the finding was the same before and after BSCPA. In the remaining 10 patients with reduced $\mathrm{RV}$ function postoperatively, RV dysfunction was seen for the first time after BSCPA.

\section{Relationship Among Relative Size of Tricuspid Annulus, TAPSE, and RV Function}

Patients with a preoperative $Z$ value of the tricuspid annulus greater than 1.5 also had a larger TAPSE/age ratio (68.3 $\pm 12.1)$ than the patients with a smaller annulus $(58.4 \pm 6.6$; $P<.001)$. Postoperatively, this relationship between the TAPSE values and the $Z$ value of the tricuspid annulus could not be confirmed $(P=.115)$.

Postoperative RV function was not dependent on the preoperative $(P=.862)$ or postoperative $(P=.179) Z$ value of the tricuspid annulus.

The patients with postoperatively reduced RV function had a lower postoperative TAPSE/age ratio $(44.1 \% \pm$ $10.8 \%$ ) than the patients with normal RV function $(54.4 \% \pm 9.0 \% ; P=.015)$.

\section{DISCUSSION}

Significant TR is known to reduce the long-term hemodynamic performance of the systemic RV in patients with HLHS and is a risk factor for early and late adverse events. ${ }^{1,2}$ Some studies have suggested that the grade of TR will decrease after BSCPA without surgical intervention on the $\mathrm{TV}^{7}$ Our data have shown that effective volume unloading might reduce TV size but does not necessarily influence TR.

\section{TV Regurgitation}

The prevalence of significant TR in our patients was 13\% before BSCPA, similar to previously reported data. ${ }^{10}$ The 
TABLE 2. Echocardiographic details of patients with significant tricuspid regurgitation

\begin{tabular}{|c|c|c|c|c|c|c|c|c|c|c|c|}
\hline \multirow[b]{2}{*}{ Group } & \multirow[b]{2}{*}{$\begin{array}{l}\text { Patient } \\
\text { ID }\end{array}$} & \multirow{2}{*}{$\begin{array}{c}\text { Interval to } \\
\text { echocardiogram } \\
\text { after BSCPA (mo) }\end{array}$} & \multicolumn{2}{|c|}{ TR } & \multicolumn{2}{|c|}{$Z$ value tricuspid annulus } & \multicolumn{3}{|c|}{ Valve morphology } & \multicolumn{2}{|c|}{ RV function } \\
\hline & & & $\begin{array}{l}\text { Before } \\
\text { BSCPA }\end{array}$ & $\begin{array}{c}\text { After } \\
\text { BSCPA }\end{array}$ & $\begin{array}{r}\text { Before } \\
\text { BSCPA }\end{array}$ & $\begin{array}{c}\text { After } \\
\text { BSCPA }\end{array}$ & $\begin{array}{c}\text { Anterior } \\
\text { leaflet }\end{array}$ & $\begin{array}{l}\text { Septal } \\
\text { leaflet }\end{array}$ & $\begin{array}{c}\text { Posterior } \\
\text { leaflet }\end{array}$ & $\begin{array}{l}\text { Before } \\
\text { BSCPA }\end{array}$ & $\begin{array}{c}\text { After } \\
\text { BSCPA }\end{array}$ \\
\hline 2 & 5 & 17.87 & III* & I & 2.21 & 0.32 & Normal & Normal & Normal & $\begin{array}{c}\text { Moderately } \\
\text { reduced }\end{array}$ & Normal \\
\hline 2 & 10 & 49.48 & $\mathrm{III}^{*}$ & 0 & 2.79 & NA & Prolapse & Restriction & Normal & Normal & $\begin{array}{l}\text { Mildly } \\
\text { reduced }\end{array}$ \\
\hline 2 & 42 & 23.57 & III* & II & 0.95 & 0.18 & Normal & Restriction & Normal & Normal & Normal \\
\hline 2 & 51 & 12.85 & III* & II & 1.96 & 0.99 & Normal & Prolapse & Normal & Normal & Normal \\
\hline 2 & 52 & 15.77 & III* & II & 1.41 & 0.82 & Prolapse & Restriction & Normal & Normal & Normal \\
\hline 2 & 74 & 11.25 & III* & II & 1.13 & 1.43 & Prolapse & Restriction & Prolapse & Normal & Normal \\
\hline 2 & 78 & 0.69 & III* & II & 2.44 & 1.55 & Prolapse & Normal & Normal & Normal & Normal \\
\hline 3 & 2 & 21.80 & III* & $\mathrm{IV}^{*}$ & NA & 2.35 & Normal & Normal & Normal & $\begin{array}{l}\text { Mildly } \\
\text { reduced }\end{array}$ & $\begin{array}{l}\text { Mildly } \\
\text { reduced }\end{array}$ \\
\hline 3 & 39 & 11.80 & III* & $\mathrm{IV}^{*}$ & 1.75 & 1.04 & $\begin{array}{l}\text { Prolapse, } \\
\text { ruptured } \\
\text { chordae }\end{array}$ & Restriction & Normal & $\begin{array}{l}\text { Mildly } \\
\text { reduced }\end{array}$ & Normal \\
\hline 3 & 70 & 0.36 & III* & III* & 0.60 & -0.14 & Prolapse & Restriction & Normal & Normal & Normal \\
\hline 3 & 77 & 8.36 & III* & III* & 2.36 & 1.63 & Normal & Restriction & Normal & Normal & Normal \\
\hline 3 & 8 & 18.52 & II & $\mathrm{IV}^{*}$ & NA & 1.76 & $\begin{array}{l}\text { Prolapse, } \\
\text { perforation }\end{array}$ & Restriction & Normal & Normal & Normal \\
\hline 3 & 18 & 15.05 & II & III* & NA & 1.24 & Normal & Restriction & Normal & Normal & $\begin{array}{l}\text { Mildly } \\
\text { reduced }\end{array}$ \\
\hline 3 & 23 & 57.21 & II & III* & 1.33 & 2.46 & Prolapse & Restriction & Normal & Normal & Normal \\
\hline 3 & 24 & 44.07 & II & $\mathrm{IV}^{*}$ & 0.87 & 0.75 & Prolapse & Normal & Normal & Normal & Normal \\
\hline 3 & 35 & 32.75 & II & III* & 2.17 & 0.25 & Prolapse & Restriction & Normal & Normal & Normal \\
\hline 3 & 47 & 30.23 & II & $\mathrm{IV}^{*}$ & 1.65 & 1.88 & Prolapse & Restriction & Normal & Normal & Normal \\
\hline 3 & $82 \dagger$ & 1.90 & I & III* & NA & 2.00 & Normal & Normal & Normal & Normal & $\begin{array}{c}\text { Moderately } \\
\text { reduced }\end{array}$ \\
\hline
\end{tabular}

$B S C P A$, Bidirectional superior cavopulmonary anastomosis; $T R$, tricuspid regurgitation; $N A$, data not available. *Significant TR. $\dagger$ Died before total cavopulmonary connection.

follow-up echocardiograms revealed an unchanged percentage of patients with significant TR after BSCPA. Considering the individual patients, almost one half exhibited no change in the grade of TR and $40 \%$ exhibited a change of \pm 1 grade (ie, postoperative grade of TR was 1 grade more or 1 grade less than the preoperative grade of TR). The patients with significant TR preoperatively had a larger annulus than the rest of the series, and, similarly, the patients with significant TR postoperatively had a larger TV annulus than those with nonsignificant TR postoperatively. These findings have demonstrated the importance of TV annulus dilation in the pathophysiology of TR. It is known that the morphology of the TV varies in patients with HLHS. ${ }^{11}$ In our study, the most common pathology of TV leaflets in the patients with significant TR was restriction of the septal leaflet and prolapse of the anterior leaflet; the leaflets were only seldom described as normal.

\section{TV Annulus}

Before BSCPA, patients with HLHS have a faster rate of tricuspid annulus growth than the patients with normal, biventricular hearts. ${ }^{6}$ Our data have indirectly confirmed this finding, because the TV annulus in our series was larger than in the normal population. BSCPA diverts the blood flow from the superior vena cava to the lungs and, therefore, reduces the volume load of the systemic RV. ${ }^{5}$ Although this has been shown even in patients in whom an additional source of pulmonary blood flow has been preserved after BSCPA, ${ }^{11}$ it is important to note that, as we previously reported, we never leave any additional blood flow when performing BSCPA. ${ }^{12}$ Seliem and colleagues ${ }^{13}$ reported that the RV end-diastolic volume decreases by $33 \%$ after BSCPA. In our patient population, the mean $Z$ value of the TV annulus decreased significantly after BSCPA in all patients without no significant TR postoperatively. This is in accordance with work by Michelfelder and colleagues, ${ }^{6}$ who showed that the decreased ventricular volume after BSCPA normalizes the rate of tricuspid annulus growth. However, in the present study, the relative size of the TV annulus did not change after BSCPA in the patients with significant TR postoperatively. Significant TR after BSCPA leads to high preload and might neutralize RV remodeling.

\section{Tricuspid Annular Plane Systolic Excursion}

To achieve a better understanding of the changes in the RV after BSCPA, we examined the TAPSE. The measurement of 


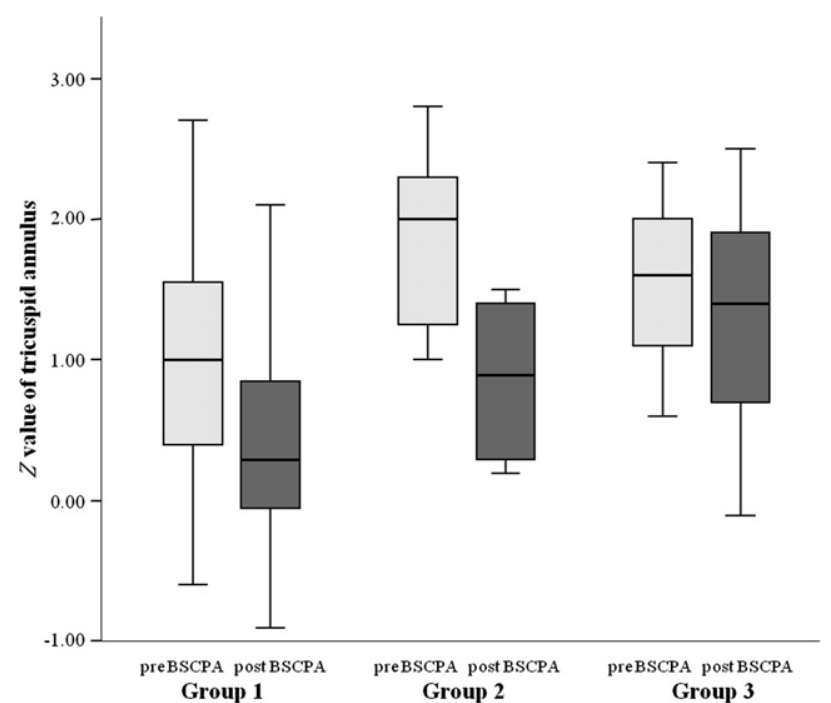

FIGURE 2. $Z$ value of tricuspid annulus, before and after bidirectional superior cavopulmonary anastomosis (BSCPA). See text for details of patient groups. Upper and lower box plot margins represent interquartile range; middle bar indicates median; vertical lines represent data within 1.5-fold interquartile range above the third and below the first quartile.

TAPSE has been described as easily reproducible and reported to have high specificity and negative predictive power for detecting abnormal RV systolic function in adult patients. ${ }^{14}$ The largest TAPSE values are found in the context of normal RV and LV systolic function. ${ }^{15}$ Few reports have

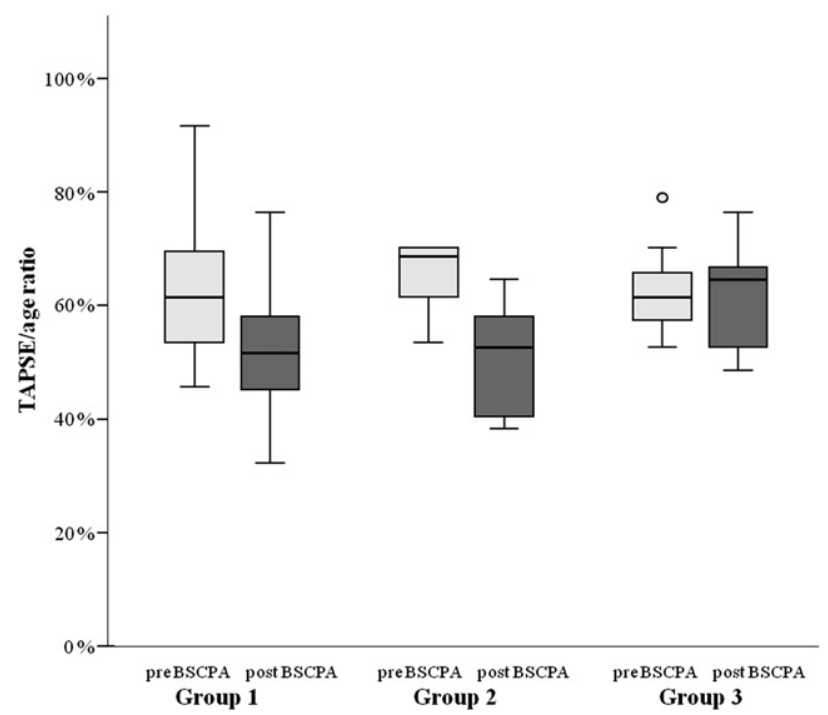

FIGURE 3. Tricuspid annular plane systolic excursion (TAPSE)/age ratio before and after bidirectional superior cavopulmonary anastomosis (BSCPA); $100 \%$ depicts mean expected value of normal population. See text for details of patient groups. Upper and lower box plot margins represent interquartile range; middle bar indicates median; vertical lines represent data within 1.5 -fold interquartile range above third and below first quartile; data 1.5 interquartile range higher than third quartile were considered outliers and shown with circles. addressed TAPSE in children with congenital heart disease. Because it has been shown that TAPSE is affected by increasing age, we evaluated TAPSE indexed to age, as suggested by Koestenberger and colleague. ${ }^{9}$ Nii and colleagues ${ }^{16}$ have suggested that TV annular dynamics are different in patients with HLHS because of a lack of interaction with the left ventricle. All the patients in our series had reduced TAPSE compared with the normal values for the corresponding age group, both before and after BSCPA, although most had normal RV function. In the patients with nonsignificant TR, TAPSE was significantly reduced after BSCPA. In the presence of significant TR, no operation-related change in TAPSE was noted. This suggests that TAPSE is directly related to RV preload status: before BSCPA (with the aortopulmonary, modified Blalock-Taussig, or Sano shunt), the preload and TAPSE levels are greater than the post-BSCPA levels. RV preload and TAPSE only remain high after BSCPA in patients with significant TR. It is also of note that TAPSE is a volume-dependent parameter. Owing to the larger difference between the systolic and diastolic RV volumes, the TAPSE is greater when TR is present.

\section{RV Function}

The effect of volume overload on the function of the systemic RV in patients with HLHS has been extensively investigated, leading to the current consensus of favoring early unloading. ${ }^{17}$ Hansen and colleagues ${ }^{10}$ described a deterioration of RV function after BSCPA. In their study, the followup echocardiograms were done 2 weeks after BSCPA, and the RV dysfunction might have been caused by the effects of the cardiopulmonary bypass. In our study, the prevalence of reduced RV function was also greater after BSCPA. Most of the patients who had reduced RV function postoperatively had a normally functioning ventricle before the operation. Because the interval between BSCPA and the second echocardiogram for each of these patients was more than 8 weeks, the postoperative RV dysfunction was unlikely to be a transient effect due to some element of the operation. A partial explanation for this finding is that morphologically the $\mathrm{RV}$ is required to support the systemic circulation in patients with HLHS. However, because the mechanisms of how hypoplasia of the left heart affects the function of the systemic RV in patients with HLHS are complex and not completely understood, additional detailed investigation of the morphology and function of the systemic RV are needed to clarify this phenomenon.

\section{Potential Clinical Implications}

A recent study by Elmi and colleagues ${ }^{2}$ showed that approximately one quarter of all HLHS survivors will have undergone surgical TV procedures within the first 10 years of life. They noted that most of the TV interventions are performed in the early years of childhood but that a certain percentage of children require valve surgery at a later date, after 
completion of univentricular palliation. ${ }^{2}$ The surgical strategy is individual, depends on the specific valve morphology, and includes variations in annuloplasty (De Vega, posterior leaflet obliteration) and leaflet/chordal reconstruction. Several publications have reported good outcomes for surgical repair of the systemic TV in patients with HLHS.,18-20 However, the correct timing for valvuloplasty in patients with a single ventricle is still debated. A recent study by Dinh and colleagues ${ }^{20}$ showed an early success rate of $71 \%$ after tricuspid repair, with most patients maintaining good valve function during the follow-up period. Although younger patients had worse early outcomes, no significant differences were seen in age or weight at tricuspid repair between the success and failure groups at the late outcome point. ${ }^{20}$ Some studies have suggested that regurgitation at the atrioventricular valve in patients with univentricular heart might improve after BSCPA without concomitant valvuloplasty, ${ }^{7}$ although others have argued the opposite and suggest a TV repair at BSCPA if more than moderate regurgitation is present. ${ }^{10}$ Our data have shown that most of the patients with HLHS will experience a reduction in the relative size of the TV annulus after BSCPA. However, this remodeling of the RV does not lead to an improvement in TR. The patients with significant TR after BSCPA had a larger TV annulus than those with nonsignificant TR. A possible explanation might be that significant TR after BSCPA neutralizes RV remodeling or, vice versa, when $\mathrm{RV}$ remodeling does not lead to a reduction of the annulus, significant TR remains after BSCPA.

It can therefore be assumed that, without surgical intervention, the grade of TR present at BSCPA will remain unchanged until completion of the univentricular palliation, which usually occurs 1 to 2 years after BSCPA. During this time, significant TR might have a detrimental effect on the long-term function of the RV. Taking all this into account, together with the good results after tricuspid valvuloplasty, which have been reported even in younger children with HLHS, it can be postulated that, although an individual approach to each patient is necessary, in the patients with significant TR (moderate and severe), TV repair should be considered at the time of BSCPA.

\section{Study Limitations}

The present study was retrospective, and the echocardiograms were obtained from the hospital archive. Thus, it was not possible to measure all the desired parameters from the available echocardiographic loops. Although the study group was relatively large, the number of the patients with significant TR was small. This might have limited the value of the statistical evaluation of the groups.

\section{CONCLUSIONS}

Unloading of the right ventricle by BSCPA in patients with HLHS promotes the remodeling of the systemic RV, which leads to a decrease in the relative size of the TV annulus. However, this remodeling of the RV does not improve the degree of TR. In the presence of significant TR, TV repair should be considered at the time of BSCPA.

\section{References}

1. Sano S, Huang SC, Kashara S, Yoshizumi K, Kotani Y, Ishino K. Risk factors for mortality after the Norwood procedure using right ventricle to pulmonary artery shunt. Ann Thorac Surg. 2009;87:178-86.

2. Elmi M, Hickey EJ, Williams WG, Van Arsdell G, Caldarone CA, McCrindle BW. Long-term tricuspid valve function after Norwood operation. J Thorac Cardiovasc Surg. 2011;142:1341-7.

3. Ohye RG, Gomez CA, Goldberg CS, Graves HL, Devaney EJ, Bove EL. Tricuspid valve repair in hypoplastic left heart syndrome. J Thorac Cardiovasc Surg. 2004; 127:456-72.

4. Barron DJ, Kilby MD, Davie SB, Wright JG, Jones TJ, Brawn WJ. Hypoplastic left heart syndrome. Lancet. 2009;374:551-64.

5. Jacobs ML, Rychik J, Rome JJ, Apostopoulou S, Pizarro C, Murphy JD, Norwood WI Jr. Early reduction of the volume work of the single ventricle: the hemi-Fontan operation. Ann Thorac Surg. 1996;62:456-61.

6. Michelfelder EC, Kimball TR, Pearl JM, Manning PB, Beekman RH III. Effect of superior cavopulmonary anastomosis on the rate of tricuspid annulus dilatation in hypoplastic left heart syndrome. Am J Cardiol. 2002;89: 96-8.

7. Mahle WT, Cohen MS, Spray TL, Rychik J. Atrioventricular valve regurgitation in patients with single ventricle: impact of the bidirectional cavopulmonary anastomosis. Ann Thorac Surg. 2001;72:831-5.

8. Pettersen MD, Du W, Skeens ME, Humes RA. Regression equations for calculation of $\mathrm{Z}$ scores of cardiac structures in a large cohort of healthy infants, children and adolescents: an echocardiographic study. J Am Soc Echocardiogr. 2008;21: 922-34.

9. Koestenberger M, Ravekes W, Everett AD, Strueger HP, Heinzl B, Gamillscheg A, et al. Right ventricular function in infants, children and adolescents: reference values of the tricuspid annular plane systolic excursion (TAPSE) in 640 healthy patients and calculation of Z score values. J Am Soc Echocardiogr. 2009;22:715-9.

10. Hansen JH, Uebing A, Furck AK, Scheewe J, Jung O, Fischer G, et al. Risk factors for adverse outcome after superior cavopulmonary anastomosis for hypoplastic left heart syndrome. Eur J Cardiothorac Surg. 2011;40:e43-9.

11. Allgood NL, Alejos J, Drinkwater DC, Laks H, Williams RG. Effectiveness of the bidirectional Glenn shunt procedure for volume unloading in the single ventricle patient. Am J Cardiol. 1994;74:834-6.

12. Schreiber C, Cleuziou J, Cornelsen JK, Hörer J, Eicken A, Lange R. Bidirectional cavopulmonary connection without additional pulmonary blood flow as an ideal staging for functional univentricular hearts. Eur J Cardiothorac Surg. 2008;34 550-5.

13. Seliem MA, Baffa JM, Vetter JM, Chen SL, Chin AJ, Norwood WI. Changes in right ventricular geometry and heart rate early after hemi-Fontan procedure. Ann Thorac Surg. 1993;55:1508-12.

14. Ghio S, Recusani F, Klersy C, Sebastiani R, Laudisa ML, Campana C, et al. Prognostic usefulness of the tricuspid annular plane systolic excursion in patients with congestive heart failure secondary to idiopathic or ischemic dilated cardiomyopathy. Am J Cardiol. 2000;85:837-42.

15. Lopez-Candales A, Rajagopalan N, Saxena N, Gulyasy B, Edelman K, Bazaz R. Right ventricular systolic function is not the sole determinant of tricuspid annular motion. Am J Cardiol. 2006;98:973-7.

16. Nii M, Guerra V, Roman KS, MacGowan CK, Smallhorn JF. Three-dimensional tricuspid annular function provides insight into the mechanisms of tricuspid valve regurgitation in classic hypoplastic left heart syndrome. J Am Soc Echocardiogr. 2006;19:391-402.

17. Adachi I, Ueno T, Ichikawa H, Kagisaki K, Haruki I, Hoashi T, et al. Effect of ventricular volume before unloading in a systemic ventricle supporting Fontan circulation. Am J Cardiol. 2011;107:459-65.

18. Bove EL, Ohye RG, Devaney EJ, Hirsch J. Tricuspid valve repair for hypoplastic left heart syndrome and the failing right ventricle. Semin Thorac Cardiovasc Surg Pediatr Card Surg Annu. 2007;10:101-4.

19. Reyes A II, Bove EL, Mosca RS, Kulik TJ, Ludomirsky A. Tricuspid valve repair in children with hypoplastic left heart syndrome during staged surgical reconstruction. Circulation. 1997;96(9 Suppl):II341-3. 
20. Dinh DC, Gurney JG, Donohue JE, Bove EL, Hirsch JC, Devaney EJ, et al. Tricuspid valve repair in hypoplastic left heart syndrome. Pediatr Cardiol. 2011;32: 599-606.

\section{Discussion}

Dr Shunji Sano (Okayama, Japan). Just to clarify, the partial cavopulmonary connection (PCPC) means the bidirectional Glenn or hemi-Fontan?

Dr Kasnar-Samprec. We almost always performed a bidirectional Glenn.

Dr Pedo del Nido (Boston, Mass). First, congratulations for a very timely study. I think all of us are very interested in the tricuspid valve in this particular patient group, and your information is actually going to be very useful for decision-making. I also want to thank you for sending me the manuscript with plenty of time.

I would like to try to delve slightly deeper into some of the information that you provided and to really try to understand your recommendation, because I agree with you, but I think the rationale still needs to be discussed.

The first question I have for you is that if we focus on your group 2 , the patients who had improvement in their volume size and tricuspid valve annulus with only the PCPC, if I understand it correctly, the vast majority of those patients, had some degree of significant TR, and they improved on their own without any intervention on the tricuspid valve. Is that correct?

Dr Kasnar-Samprec. Yes, 7 of the patients did.

Dr del Nido. If that is the case, can you tell me something about the surgical factors that might have contributed to that. In other words, how many of those patients had shunts versus right ventricle to pulmonary artery conduits and what was their Qp/Qs at the time they underwent the stage 2 procedure?

Dr Kasnar-Samprec. These are the patients operated on between 2001 and 2010. In the early years, we mostly used aortopulmonary shunts or modified Blalock-Taussig shunts. Later, we were using the right ventricle to pulmonary artery conduits as often as possible. Studying the 3 groups separately, no significant difference was seen between the number of Sano shunts and the number of other shunts used. So, the groups were approximately the same. We had approximately one quarter of the aortopulmonary shunts or modified Blalock-Taussig shunts in all groups.

Dr del Nido. But you have no information about the Qp/Qs?

Dr Kasnar-Samprec. No. Unfortunately, I have no information on the Qp/Qs.

Dr del Nido. I am sure they all had catheters place, so I think that information might be available.

Dr Kasnar-Samprec. Yes, definitely.

Dr del Nido. The other question I had, and really it is more of a concern, and that is that you had a median follow-up of 17 months, which is great, because it is important to know what happens within that period, but your range was from 7 days to 57 months.

Dr Kasnar-Samprec. Yes.

Dr del Nido. My question is: Clearly your technique evolved during those 10 years, were there differences in the follow-up period for the 3 different groups?

Dr Kasnar-Samprec. No.

Dr del Nido. No differences?
Dr Kasnar-Samprec. No, there were no differences. We had, all together, 9 patients who underwent follow-up echocardiography between 7 and 28 days postoperatively. Actually, only 1 patient at day 7, the next 4 patients at approximately day 14, and the rest later.

We sometimes operate on patients who travel from other countries to our institution, and we did not have all the necessary data for our study, so we could not reevaluate more recent echocardiograms. However, the median time for each group was approximately 17 months. It was 17 months for group 1, 16 for group 2, and 18 for group 3 . The mean values were also approximately the same.

Dr del Nido. Okay. Thank you.

My next question relates to your recommendation, which is that one should consider tricuspid valve repair if the patient has more than mild tricuspid regurgitation, moderate or severe, at the stage 2 procedure, which gets at the predictive value of your study. You have 2 groups, 1 group that got better on its own, which was group 2 , and 1 group that did not. What would you recommend as a procedure that would cover both of those groups?

Dr Kasnar-Samprec. When we started the study, we clearly first looked at whether there is something which we could use to determine directly before the PCPC, yes, this patient definitely needs tricuspid surgery; or no, this patient definitely does not. Our data unfortunately did not show that. So, the 2 graphs I showed are actually based on the knowledge of what happened after the PCPC.

It would clearly be very easy to say, yes, in group 3, the annulus will not change, so we should do an annuloplasty. In group 2, we do not have to anything. However, this is unfortunately not the case. At the time when we are planning the PCPC, we cannot predict which patient will have an improvement of significant TR or which will develop significant TR. So, this is definitely a very difficult question.

Dr del Nido. The flip side of that coin is that if you are suggesting annuloplasty, the annulus size in all your patients was within 2 standard deviations of normal. So, they were all normal. Thus, reducing the annulus might or might not help very much at all. Also, in fact, the worst group, group 3, had no change in valve annulus, and it was normal. So, it begs the question.

Dr Kasnar-Samprec. It was normal; however, it was larger than in the normal population, just as in all of other patients before PCPC.

Dr del Nido. Usually within plus or minus 2 standard deviations is considered normal. All your patients, if I understand it correctly, were within that range.

The other question that I have is that if you consider the Single Ventricle Reconstruction trial, which was a large trial, they have a very similar experience. The incidence of more than mild tricuspid regurgitation was slightly greater, at stage 2 , it was about $18 \%$. However, if you look 1 year later, or 14 months later, the incidence was the same, independent of what was done to those children.

The question is: Were those the same children? Also, I think what your study is showing is that there are different groups. Some children definitely improve by just having the volume load removed and then there are those who do not. But we still do not have a very good predictor of which children will or will not improve. 
Dr Kasnar-Samprec. Definitely, we do not have a good predictor. What I did not show here is that we described the morphology of the TV in all patients who had significant TR. Usually the anterior leaflet was larger, the septal leaflet somewhat smaller, and so on. So, there are things a surgeon can do, except make the annulus smaller. There were only 2 cases in which our cardiologist described the leaflets as completely normal. All other patients had something that could have theoretically been addressed at the PCPC.

Dr J. William Gaynor (Philadelphia, Pa). I enjoyed your paper, too, and I agree this is a very important topic. I also agree with Pedro that knowing the degree of volume overload estimated by the Qp/Qs is very important.

Two other questions, and I might have missed this. Were these echocardiographic measurements taken from reports or were the echocardiograms read again for this study?

Dr Kasnar-Samprec. They were read again. A single experienced observer looked at every echocardiogram again.

Dr Gaynor. Then second, 1 issue we found that affects the severity of TR in these children is any degree of residual arch obstruction. Even fairly mild degrees can cause them to have TR. Thus, sometimes relief of the arch obstruction can result in an improvement in the TR. So, do you have any data about any residual arch obstruction in any of these children? Had any of them undergone balloon dilation or other surgical interventions?

Dr Kasnar-Samprec. Definitely. We perform an angiogram directly before PCPC. I do not have the data regarding the Qp/Qs here. However, when our cardiologists find a residual gradient in the aorta, they perform balloon angioplasty. The patients who underwent angioplasty before PCPC, they are always controlled afterward as well. Most of the patients in this study had no gradient or had a relatively mild gradient. I could say that this should not be an issue in this study.

Dr Gaynor. But I think it is an important item to check.
Dr Kasnar-Samprec. Definitely.

Dr Glen Van Arsdell (Toronto, Ontario, Canada). It is an interesting topic and a difficult topic. One of the factors that is becoming clear is that we do not volume unload as much as we think. Magnetic resonance imaging data have shown, when magnetic resonance imaging is done later, the patients have a Qp/Qs of about 0.8 .

It also is clear that many of them have morphologic problems that you considered. So, I wondered in the subset of patients with improvement, did you look to see whether their valve had a morphologic problem or whether with the temporary volume unloading that occurs, it was the patients with annular dilation who improved? Were you able to differentiate on that basis who might show improvement?

Dr Kasnar-Samprec. We studied all the patients who had, at any time, significant TR, we described extra the morphology of the valves. However, the morphology of the valves was not significantly different among the groups.

Dr Gerhard Ziemer (Chicago, Ill). I might have missed the information; however, to judge these outcomes, one should know something about the intraoperative course, such as surgery performed on bypass, off bypass, and if on bypass, how long were the bypass times. Because this could have some effect on the myocardial and pulmonary function. You did not present this.

Dr Kasnar-Samprec. Do you mean during the Norwood operation?

Dr Ziemer. No, during this operation, the Glenn anastomosis, did you do it on bypass or off bypass?

Dr Kasnar-Samprec. We did all of them on bypass.

Dr Ziemer. Well, if you did all on bypass, it would be interesting to know whether those who did worse by any measure, had a longer bypass run and just were worse because of that. This is just information one would like to have, I think.

Dr Kasnar-Samprec. Thank you for the suggestion. 